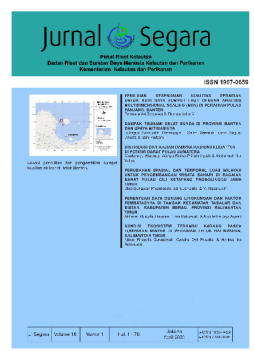

JURNAL SEGARA

http://ejournal-balitbang.kkp.go.id/index.php/segara

ISSN : 1907-0659

e-ISSN : 2461-1166

Nomor Akreditasi: 766/AU3/P2MI-LIPI/10/2016

\title{
PENENTUAN DAYA DUKUNG LINGKUNGAN DAN FAKTOR PEMBATASNYA DI TAMBAK KECAMATAN TABALAR DAN BIATAN, KABUPATEN BERAU, PROVINSI KALIMANTAN TIMUR
}

\section{DETERMINATION OF ENVIRONMENTAL CARRYING CAPACITY AND ITS LIMITING FACTOR IN BRACKISHWATER PONDS OF TABALAR AND BIATAN SUBDISTRICTS, BERAU DISTRICT, EAST KALIMANTAN PROVINCE}

\author{
Akhmad Mustafa, Hasnawi, Erna Ratnawati, \& Andi Indra Jaya Asaad \\ Balai Riset Perikanan Budidaya Air Payau dan Penyuluhan Perikanan \\ Jl. Makmur Dg. Sitakka No. 129 Turikale, Maros 90512, Sulawesi Selatan \\ Diterima: 5 Agustus 2019; Diterima Setelah Perbaikan: 21 Maret 2020; Disetujui Terbit: 6 Juni 2020
}

\begin{abstract}
ABSTRAK
Daya dukung dan faktor pembatasnya memiliki pengaruh penting terhadap keberhasilan kegiatan akuakultur, termasuk budidaya tambak di Kabupaten Berau. Oleh karena itu dilakukan penelitian yang bertujuan untuk menentukan daya dukung lingkungan dan faktor pembatasnya di tambak Kecamatan Tabalar dan Biatan, Kabupaten Berau, Provinsi Kalimantan Timur agar produktivitas tambak dapat ditingkatkan dan berkelanjutan. Faktor yang dipertimbangkan dalam analisis daya dukung lingkungan dan faktor pembatasnya adalah topografi dan hidrologi, kualitas tanah, kualitas air, dan iklim. Penentuan daya dukung lingkungan dalam penelitian ini dengan menggunakan sistem pembobotan dan faktor pembatas. Hasil penelitian menunjukkan bahwa daya dukung lingkungan di kawasan pertambakan di Kecamatan Tabalar dan Biatan adalah masing-masing 67,36 dan 64,58\%, sehingga luas tambak yang dapat didukung berturut-turut: 533,95 dan 38,50 ha. Di Kecamatan Tabalar dan Biatan didapatkan faktor pembatas sedang dari daya dukung lingkungan tambak berupa $\Delta \mathrm{pH}\left(\mathrm{pH}_{\mathrm{F}}-\mathrm{pH}_{\mathrm{FOX}}\right)$ tanah, $\mathrm{C}$ organik tanah, $\mathrm{N}$ total tanah, dan bahan organik total air, sedangkan faktor pembatas berat berupa $\mathrm{PO}_{4}$ air, $\mathrm{NH}_{3}$ air, dan bulan kering. Untuk mengurangi faktor pembatas sehingga meningkatkan daya dukung lingkungan tambak disarankan untuk menerapkan konservasi lahan, meningkatkan kesuburan tanah, dan mengelola air secara tepat.
\end{abstract}

Kata Kunci : Daya dukung lingkungan, faktor pembatas, Kabupaten Berau, tambak.

\section{ABSTRACT}

Carrying capacity and its limiting factors have important influence on the success of aquaculture operations, including brackishwater ponds culture in Berau District. For that, a study was carried out to determine environmental carrying capacity and its limiting factors in brackishwater ponds of Tabalar and Biatan Subdistricts, Berau District, East Kalimantan Province so that brackishwater pond productivity could be improved and sustainable. Factors considered in the analysis of environmental carrying capacity and its limiting factors are topography and hydrology, soil quality, water quality, and climate. Determination of environmental carrying capacity was done by using a weighting system and the limiting factors. Results show that environmental carrying capacity in brackishwater pond of Tabalar and Biatan Subdistricts were 67.36 and $64,58 \%$, respectively, so that brackishwater ponds that could be supported were 533.95 and 38.50 ha, respectively. In Tabalar and Biatan Subdistricts, there is a moderate limiting factor from the environmental carrying capacity in the form of $\Delta$ $\mathrm{pH}\left(\mathrm{pH}_{\mathrm{F}}-\mathrm{pH}_{\mathrm{FOX}}\right)$ of soil, soil organic $\mathrm{C}$, soil total $\mathrm{N}$, and water total organic matter, while the severe limiting factors are water $\mathrm{PO}_{4}$, water $\mathrm{NH}_{3}$, and dry month. To reduce limiting factors so as to increase environmental carrying capacity of brackishwater pond, it is recommended to apply land conservation, increase soil fertility, and manage water appropriately.

Keywords : Berau District, brackishwater pond, environmental carrying capacity, limiting factor.

Corresponding author:

Jl. Pasir Putih I Ancol Timur, Jakarta Utara 14430. Email: akhmadmustafa@yahoo.com 


\section{PENDAHULUAN}

Kawasan pesisir di dunia termasuk di Indonesia memiliki sumber daya alam yang beragam dengan berbagai kegiatan, yaitu perikanan, pertanian, permukiman, pelabuhan, pariwisata, dan/ atau industri. Beberapa kegiatan di kawasan ini sering melebihi daya dukungnya. Pengelolaan kawasan pesisir yang bertanggung jawab harus digunakan sebagai dasar untuk pengembangan kawasan pesisir, baik untuk perikanan budi daya (akuakultur) dan kegiatan sektor lainnya. Kabupaten Berau memiliki potensi besar dalam akuakultur terutama budi daya tambak, hal ini terlihat bahwa daerah ini menjadi penghasil udang windu (Penaeus monodon) terbesar di Kalimantan Timur (KKPNews, 2018). Tambak yang ada di Kabupaten Berau tersebar di Kecamatan Pulau Derawan, Sambaliung, Talisayan, Biatan, Tabalar, dan Gunung Tabur yang digunakan untuk budi daya udang windu dan ikan bandeng (Chanos chanos). Sampai pada 2009, luas tambak di Kabupaten Berau mencapai 3.710,7 ha dengan produksi sebesar 309,2 ton (DKP Kabupaten Berau, 2010) atau produktivitas $83,33 \mathrm{~kg} / \mathrm{ha} / \mathrm{tahun}$. Produktivitas tambak yang rendah ini perlu mendapat perhatian terutama terkait dengan daya dukung lahan tambak di kabupaten tersebut, supaya daya dukung lahan tambak dapat diketahui lebih dini sehingga alokasi sumber daya lahan tambak dapat ditentukan lebih tepat. Akibat lebih lanjut adalah konsep budi daya tambak yang berkelanjutan dapat terwujud di Kabupaten Berau. Dalam Pasal 8 Peraturan Pemerintah Republik Indonesia Nomor 26 Tahun 2008 Tentang Rencana Tata Ruang Wilayah Nasional telah ditetapkan bahwa kebijakan pengembangan kawasan budi daya meliputi: pengendalian perkembangan kegiatan budi daya agar tidak melampaui daya dukung dan daya tampung lingkungan (Sekneg RI, 2008).

Daya dukung merupakan istilah yang lebih umum untuk karakter lingkungan dan kemampuannya dalam mengakomodasi suatu kegiatan tertentu atau laju suatu kegiatan tanpa dampak yang tidak dapat diterima (Ross et al., 2013; Triyatmo et al., 2018). Daya dukung didefinisikan sebagai biomassa maksimal dari spesies yang dibudidayakan yang dapat didukung tanpa melampaui dampak maksimal yang dapat diterima terhadap spesies yang dibudidayakan dan lingkungannya (Stigebrandt, 2011; Neto et al., 2016). Sangat penting bahwa daya dukung dianggap sebagai bagian integral dari proses pengembangan dan pemilihan lokasi untuk kegiatan akuakultur, dan melekat dalam penerapan praktik-praktik yang baik dan peraturan lingkungan yang tepat untuk memastikan keberlanjutan produksi pangan berbasis akuakultur (Ross et al., 2013). Produksi akuakultur berkelanjutan harus mempertimbangkan penilaian daya dukung untuk penggunaan secara rasional sumber daya alam seperti badan air. Daya dukung merupakan faktor penting dalam menjamin siklus produksi budi daya dalam jangka waktu yang lama (Susetyo \& Santoso, 2016). Faktor lain yang sangat terkait dengan daya dukung suatu lahan adalah faktor pembatas daya dukung itu sendiri. Faktor pembatas merupakan faktor biotik dan abiotik yang dapat membatasi daya dukung dan di lain pihak dapat digunakan untuk menentukan pengelolaan lahannya untuk meningkatkan daya dukung. Identifikasi faktor pembatas merupakan langkah awal untuk menentukan cara meningkatkan kesesuaian dan daya dukung lahan (Moretto \& Francis, 2017).

Dalam praktiknya, dikenal beberapa istilah daya dukung. Daya dukung untuk akuakultur dibagi menjadi daya dukung fisik, daya dukung produksi, daya dukung lingkungan atau ekologi, dan daya dukung sosial (McKindsey et al., 2006; Bengtson, 2014; Smaal \& van Duren, 2018). Menurut Poernomo (1992) daya dukung lingkungan itu merupakan nilai kualitas lingkungan yang ditimbulkan oleh interaksi dari semua unsur atau komponen fisika, kimia, dan biologi dalam suatu kesatuan ekosistem. Penentuan daya dukung lingkungan kawasan pertambakan dengan sistem pembobotan yang mengacu pada modifikasi Poernomo (1992) yang telah diaplikasikan oleh Prasita (2007) di Kabupaten Gresik (Jawa Timur), Yulianda (2008) di Kabupaten Aceh Utara (Nanggroe Aceh Darussalam), Alifatri (2017) di Kabupaten Karawang (Jawa Barat), dan Rahayu (2017) di Kabupaten Lamongan (Jawa Timur). Berdasarkan uraian tersebut maka dilakukan penelitian yang bertujuan untuk menilai daya dukung lingkungan dan faktor pembatasnya di tambak Kecamatan Tabalar dan Biatan, Kabupaten Berau, untuk mengetahui luasan maksimal tambak yang diharapkan dapat memiliki produktivitas tinggi dan berkelanjutan serta menjadi acuan dalam penyusunan rencana tata ruang wilayah.

\section{METODE PENELITIAN}

\section{Waktu dan Lokasi Penelitian}

Penelitian dilaksanakan pada musim kemarau (curah hujan rendah) dan musim hujan (curah hujan tinggi) di kawasan tambak Kecamatan Tabalar dan Biatan, Kabupaten Berau, Provinsi Kalimantan Timur. Pengamatan pasang surut (pasut) selama 42 jam dengan interval pengamatan setiap jam dilakukan dari 23 sampai 25 Agustus 2015 di perairan Kampung Pegat, Desa Batumbuk, Kecamatan Pulau Derawan, Kabupaten Berau.

\section{Pengumpulan Data}

Data yang dikumpulkan meliputi aspek lahan berupa topografi dan hidrologi, kualitas tanah, kualitas air, dan iklim sesuai petunjuk Poernomo (1992), McKindsey et al. (2006), Prasita (2007), dan Mustafa 
(2012). Data topografi dan hidrologi, kualitas tanah, dan kualitas air diperoleh langsung dari lapangan maupun hasil analisis di laboratorium sebagai data primer, sedangkan data iklim diperoleh dari instansi terkait sebagai data sekunder.

Peubah dari faktor topografi dan hidrologi meliputi kemiringan, kestabilan pantai, pasut, dan keberadaan zona penyangga. Kemiringan diketahui melalui pengamatan di lapangan dan pengukuran dengan menggunakan Theodolite. Kestabilan pantai dan keberadaan zona penyangga diamati langsung di lapangan. Pengamatan pasut (pasang dan surut) menggunakan palem atau rambu pengamat pasut. Pasut yang diperoleh dibandingkan dengan data pasut yang tercatat pada stasiun Sungai Berau (Beting Haji) untuk waktu yang sama dengan pengamatan pasut.

Peubah kualitas tanah yang diukur langsung di lapangan berupa kedalaman tanah sampai lapisan padas dengan menggunakan bor tanah yang dilengkapi dengan meteran. Pengukuran dan pengambilan contoh tanah dilakukan pada kedalaman 0-0,2 m. Kualitas tanah yang diukur secara in situ adalah $\mathrm{pH}_{\mathrm{F}}(\mathrm{pH}$ tanah yang diukur langsung di lapangan) dengan pH-meter (Ahern et al., 2004) dan $\mathrm{pH}_{\mathrm{FOx}}(\mathrm{pH}$ tanah yang diukur di lapangan setelah dioksidasi dengan hidrogen peroksida 30\%) dengan pH-meter (Ahern et al., 2004). Untuk analisis peubah kualitas tanah lainnya, contoh tanah dimasukkan dalam kantong plastik yang selanjutnya ditempatkan dalam cool box yang berisi es sesuai petunjuk Ahern et al. (2004). Sebelumnya, sisa tumbuhan segar, kerikil dan kotoran lainnya dibuang dan bongkahan besar dikecinilkan dengan tangan. Karena seluruh contoh tanah adalah tanah sulfat masam, maka contoh tanah diovenkan pada suhu 80$85^{\circ} \mathrm{C}$ selama 48 jam (Ahern et al., 2004). Setelah kering, contoh tanah dihaluskan dengan cara ditumbuk pada lumpang porselin dan diayak dengan ayakan ukuran lubang 2,0 mm. Untuk mendapatkan ukuran partikel 0,5 mm, maka contoh berukuran partikel 2,0 $\mathrm{mm}$ ditumbuk dan disaring dengan saringan $0,5 \mathrm{~mm}$ dan selanjutnya dianalisis di Laboratorium Tanah Balai Riset Perikanan Budidaya Air Payau dan Penyuluhan Perikanan (BRPBAP3) di Maros. Kualitas tanah yang dianalisis di laboratorium meliputi karbon organik dengan metode Walkley \& Black, $\mathrm{N}$ total dengan metode Kjedahl, dan $\mathrm{PO}_{4}$ dengan metode Bray 1 (Eviati \& Sulaeman, 2009), serta tekstur dengan metode hidrometer (Agus et al., 2006).

Pengukuran dan pengambilan contoh air dilakukan di sungai, laut, saluran, dan tambak. Pengukuran dan pengambilan contoh air di tambak mengikuti titik pengambilan contoh tanah. Peubah kualitas air yang diukur langsung di lapangan adalah suhu, salinitas, oksigen terlarut, dan $\mathrm{pH}$ dengan menggunakan Hydrolab ${ }^{\circledR}$ Minisonde. Contoh air untuk analisis di laboratorium diambil dengan menggunakan Kemmerer Water Sampler dan dipreservasi mengikuti petunjuk APHA-AWWA-WEF (2012). Peubah kualitas air yang dianalisis di Laboratorium Air BRPBAP3 di Maros meliputi: amonia $\left(\mathrm{NH}_{3}\right)$, fosfat $\left(\mathrm{PO}_{4}\right)$, dan bahan organik total (BOT) mengikuti petunjuk Sutrisyani \& Rohani (2009) dan APHA-AWWA-WEF (2012).

\section{Analisis Data}

Berdasarkan data curah hujan selama lima tahun (2011 sampai dengan 2015) di Kabupaten Berau dilakukan analisis penentuan jumlah bulan kering sesuai petunjuk Schmidt \& Ferguson (1951). Data curah hujan yang sama juga digunakan untuk menentukan nilai $Q$ sebagai dasar penentuan tipe iklim mengikuti petunjuk Klasifikasi Iklim Menurut SchmidtFerguson (Schmidt \& Ferguson, 1951).

Analisis daya dukung lingkungan dengan sistem pembobotan mengacu pada modifikasi Poernomo (1992) yaitu: daya dukung lingkungan itu merupakan nilai kualitas lingkungan yang ditimbulkan oleh interaksi dari semua unsur atau komponen dalam satu kesatuan ekosistem. Dari modifikasi tersebut diduga adanya keterikatan atau hubungan antara daya dukung lingkungan dengan kesesuaian lahan di kawasan pesisir. Karena daya dukung lingkungan bersifat kuantitatif, sedangkan kesesuaian lahan bersifat kualitatif, maka metode analisis daya dukung lingkungan ini merupakan kuantifikasi dari kelas kesesuaian lahan dengan cara pemberian bobot pada kelas kesesuaian lahan.

Nilai pembobotan kualitas/karakteristik lahan berada antara 0 dan 3 . Lahan yang mempunyai kelas kesesuaian sangat sesuai diberikan bobot tertinggi yaitu 3, kelas kesesuaian lahan cukup sesuai diberikan bobot 2, kelas kesesuaian lahan kurang sesuai diberi bobot 1 , dan yang tidak sesuai diberi bobot 0 sesuai petunjuk Prasita (2007) dan Mustafa (2012).

Untuk mengetahui faktor pembatas dilakukan pembandingan (matching) nilai dari masing-masing peubah dengan baku mutu tambak yang sesuai untuk pertumbuhan komoditas air payau. Faktor pembatas lahan adalah penyimpangan dari kondisi optimal karakteristik dan kualitas lahan yang memberikan pengaruh buruk untuk berbagai penggunaan lahan (Sys et al., 1993). Berdasarkan pendapat ini maka dikembangkan metode untuk menentukan tingkat faktor pembatas lahan ke dalam empat tingkatan, yaitu: tanpa faktor pembatas atau S1; faktor pembatas ringan atau S2; faktor pembatas sedang atau S3; dan faktor pembatas berat atau N. Nilai kriteria S1, S2, S3, dan $\mathrm{N}$ untuk penentuan tingkat faktor pembatas mengacu pada Mustafa (2012). 


\section{HASIL DAN PEMBAHASAN}

Faktor topografi dan hidrologi yang meliputi kemiringan, kestabilan pantai, pasut, dan keberadaan zona penyangga di Kecamatan Tabalar dan Biatan adalah sama seperti terlihat pada Tabel 1 dan 2. Sebagai akibatnya, daya dukung lahan dari faktor topografi dan hidrologi juga sama, yaitu 91,68\%. Hal ini dikarenakan dari kedua kecamatan tersebut merupakan lokasi yang berada di kawasan pesisir dari daratan pulau utama yaitu Pulau Kalimantan, sehingga memiliki kondisi topografi dan hidrologi yang sama. Topografi dan elevasi adalah sama sebab tambak di kedua kecamatan tersebut dibangun pada bekas hutan mangrove, suatu kondisi yang relatif rata dan elevasi tanah yang rendah sehingga secara gravitasi kawasan mangrove sebelumnya masih dapat tergenang dan kering sebagai akibat dari pasut.

Pasut adalah faktor yang menentukan kemampuan suatu tambak untuk dapat digenangi secara gravitasi. Kisaran pasut yang ideal untuk tambak adalah antara 1,5 dan 2,5 m. Daerah pantai dengan kisaran pasut kurang dari 1,0 m sangat sulit untuk pengisian maupun pengeluaran air tambak secara gravitasi. Sebaliknya, daerah pantai yang kisaran pasutnya lebih dari 2,5 m juga terlalu berat untuk budi daya di tambak, sebab pematang terpaksa dibuat besar dan tinggi agar mampu menahan tekanan air waktu pasang tinggi dan surut rendah (Mustafa, 2012). Hasil pengukuran pasut menunjukkan kisaran pasut mencapai 2,85 m (Gambar 1). Hasil pengukuran pasut ini relatif sama dengan pasang surut yang diperoleh dari stasiun terdekat yaitu stasiun Sungai Berau (Beting Haji). Oleh karena itu, pasang surut di kawasan tambak yang ada di Kabupaten Berau termasuk di Kecamatan Tabalar dan Biatan diprediksi relatif sama. Namun demikian, dengan pasut yang demikian itu dibutuhkan pematang yang agak tinggi dan pematang yang agak lebar dan kokoh agar pematang dapat menahan tekanan air dari dalam tambak pada saat air surut maupun tekanan air dari luar tambak pada saat tambak tidak terisi air.

Dalam konstruksi tambak harus dilakukan penggalian agar tambak yang dikonstruksi mampu menahan air, untuk itu kedalaman tanah yang dapat digali menjadi bahan pertimbangan. Pengeboran tanah yang dilakukan sampai kedalaman $3 \mathrm{~m}$ menunjukkan bahwa semua titik-titik pengambilan contoh tanah di kedua kecamatan tersebut memiliki kedalaman tanah yang melebihi $3 \mathrm{~m}$.

Tekstur tanah merupakan perbandingan antara fraksi pasir, liat, dan debu tanah. Akan tetapi, fraksi liat adalah fraksi dari tanah yang sering digunakan sebagai peubah yang menggambarkan tekstur tanah secara keseluruhan. Seperti telah disebutkan oleh Boyd (1995) bahwa tanah tambak sering dijumpai bertekstur halus dengan kandungan fraksi liat $20-30 \%$ untuk menahan peresapan ke samping. Kandungan fraksi liat tanah $5-10 \%$ lebih baik daripada kandungan fraksi liat tanah yang lebih tinggi untuk membangun pematang jika tanah memiliki campuran partikel yang baik dengan ukuran yang berbeda (McCarty, 1998). Tanah seperti itu dapat dikerjakan lebih mudah

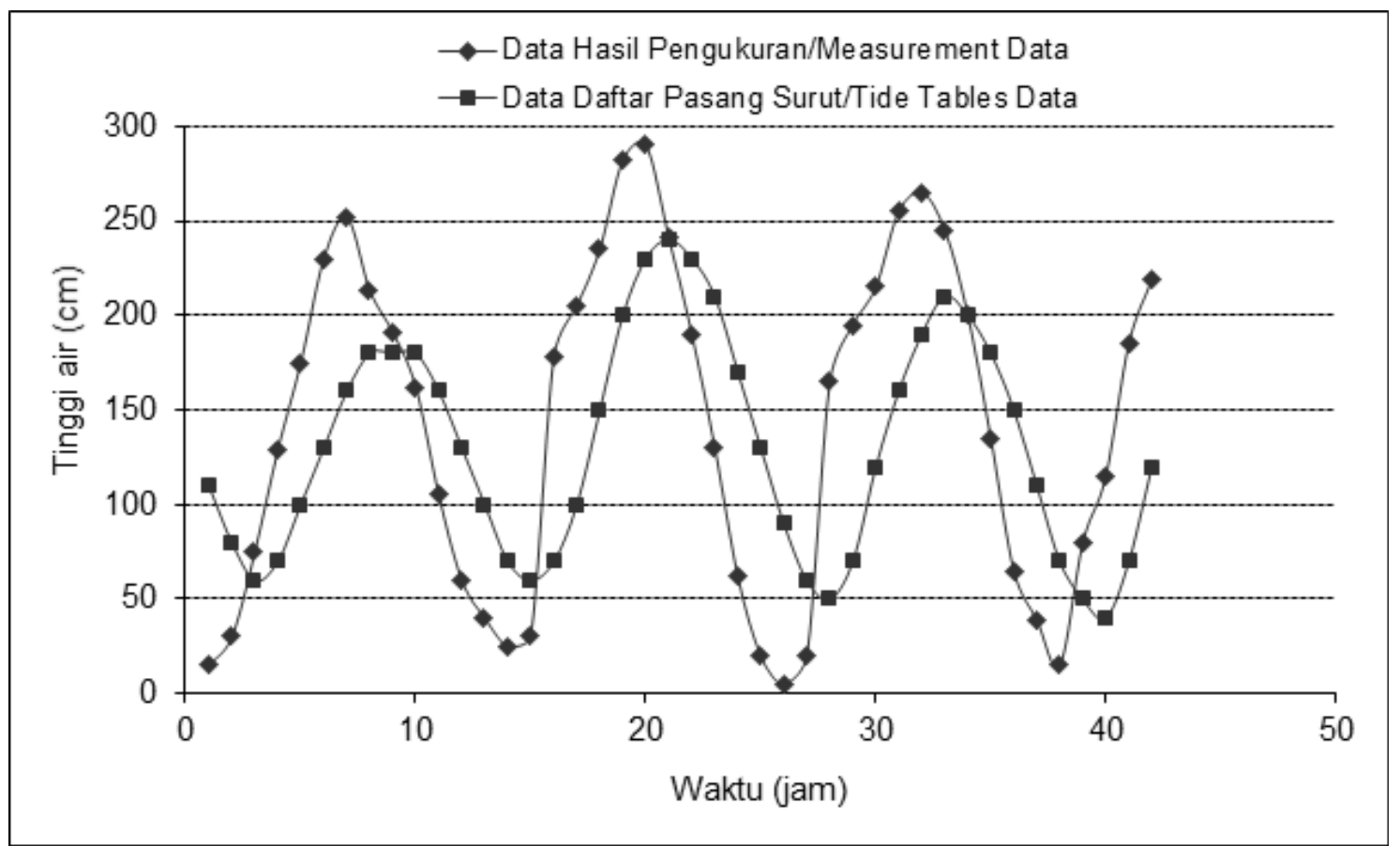

Gambar 1. Pasang surut yang terukur di Kecamatan Pulau Derawan, Kabupaten Berau, Provinsi Kalimantan Timur dan tercatat di stasiun Sungai Berau (Beting Haji). 
selama konstruksi daripada tanah dengan kandungan fraksi liat tanah yang lebih tinggi, dan tambak yang kedap air dengan pematang yang stabil masih dapat dibangun. Prosedur pengelolaan seperti pengeringan, pengolahan, pemupukan, dan pengendalian sedimen lunak juga dapat diterapkan lebih mudah di tanah dengan kandungan fraksi liat tanah yang lebih rendah (Boyd et al., 2002). Di antara kedua kecamatan di Kabupaten Berau tersebut, terlihat bahwa kandungan fraksi liat tanah Kecamatan Biatan lebih tinggi daripada di Kecamatan Tabalar.

Derajat keasaman alami $\left(\mathrm{pH}_{\mathrm{F}}\right)$ adalah $\mathrm{pH}$ tanah yang diukur langsung di lapangan dan dapat digunakan untuk indikator secara cepat keberadaan dan kepelikan tanah sulfat masam aktual. Berbeda dengan hasil pengukuran $\mathrm{pH}_{\mathrm{F}}$ adalah hasil pengukuran $\mathrm{pH}_{\mathrm{Fox}}$ yaitu $\mathrm{pH}$ yang diukur di lapangan setelah tanah diberikan $\mathrm{H}_{2} \mathrm{O}_{2} 30 \%$. Pemberian $\mathrm{H}_{2} \mathrm{O}_{2} 30 \%$ dalam pengukuran $\mathrm{pH}_{\text {Fox }}$ dimaksudkan agar potensi keasaman yang ada dalam tanah dapat teroksidasi seluruhnya secara paksa. Nilai $\Delta \mathrm{pH}\left(\mathrm{pH}_{\mathrm{F}}-\mathrm{pH}_{\mathrm{FOx}}\right)$ dapat digunakan sebagai indikator besarnya nilai potensi keasaman pada tanah sulfat masam. Dari Tabel 1 dan 2 terlihat bahwa potensi keasaman tanah tinggi yang diindikasikan dengan nilai $\Delta \mathrm{pH}$ tinggi dijumpai di Kecamatan Biatan, yaitu 4,124.

Dari faktor kualitas tanah, daya dukung lahan yang lebih tinggi dijumpai di Kecamatan Tabalar daripada Kecamatan Biatan (55,55\% vs 44,44\%). Peubah kualitas tanah yang menyebabkan lebih tingginya daya dukung lahan dari faktor kualitas tanah

Tabel 1.

Daya dukung lingkungan di kawasan pertambakan Kecamatan Tabalar, Kabupaten Berau, Provinsi Kalimantan Timur

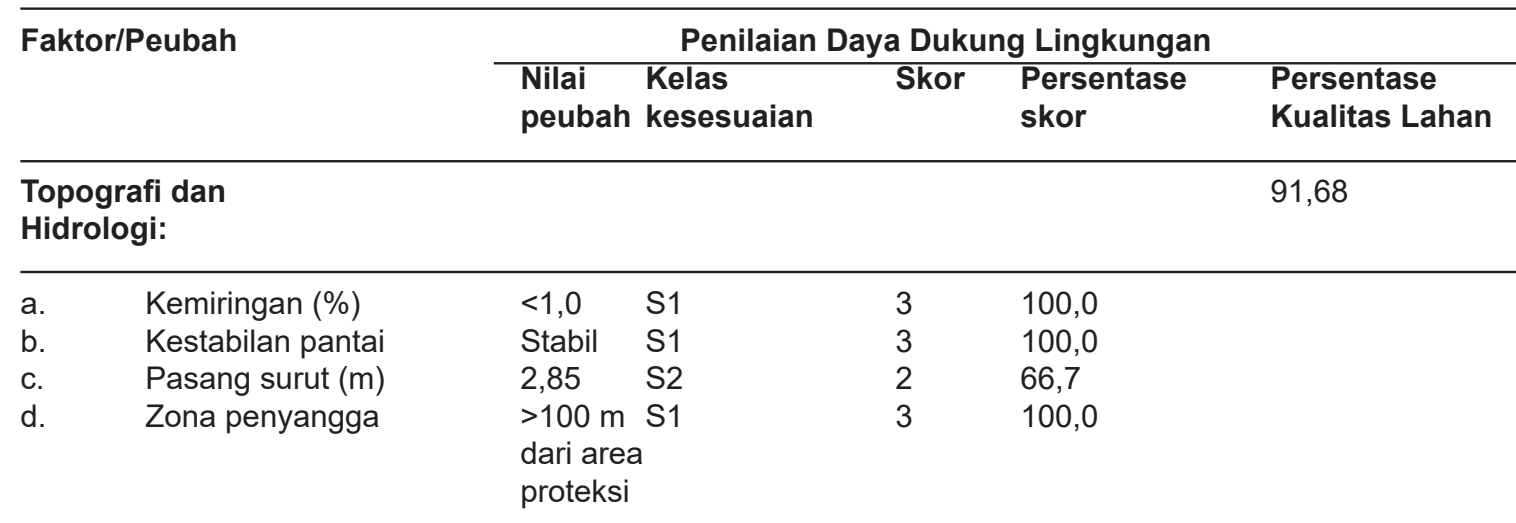

\section{Kualitas Tanah:}

55,55

$\begin{array}{llllll}\text { a. } & \begin{array}{l}\text { Kedalaman tanah } \\ \text { sampai mencapai } \\ \text { batuan }(\mathrm{m})\end{array} & >2,0 & \mathrm{~S} 1 & 3 & 100,0 \\ \text { b. } & \text { Liat }(\%) & 17,6 & \mathrm{~S} 1 & 3 & 100,0 \\ \text { c. } & \Delta \mathrm{pH}\left(\mathrm{pH}_{\mathrm{F}}-\mathrm{pH}_{\mathrm{FOX}}\right) & 3,551 & \mathrm{~S} 3 & 1 & 33,3 \\ \text { d. } & \mathrm{C} \text { organik }(\%) & 4,831 & \mathrm{~S} 3 & 1 & 33,3 \\ \text { e. } & \mathrm{N} \text { total }(\%) & 0,405 & \mathrm{~S} 2 & 2 & 66,7 \\ \text { f. } & \mathrm{PO}_{4}(\mathrm{ppm}) & 14,510 & \mathrm{~N} & 0 & 0\end{array}$

\section{Kualitas Air:}

\begin{tabular}{llllll}
\hline a. & Suhu $\left({ }^{\circ} \mathrm{C}\right)$ & 29,09 & $\mathrm{~S} 1$ & 3 & 100,0 \\
b. & Salinitas $(\mathrm{ppt})$ & 15,12 & $\mathrm{~S} 1$ & 3 & 100,0 \\
c. & $\mathrm{pH}$ & 8,13 & $\mathrm{~S} 1$ & 3 & 100,0 \\
d. & Oksigen terlarut $(\mathrm{mg} / \mathrm{L})$ & 4,95 & $\mathrm{~S} 1$ & 3 & 100,0 \\
e. & $\mathrm{NH}_{3}(\mathrm{mg} / \mathrm{L})$ & 0,702 & $\mathrm{~N}$ & 0 & 0 \\
f. & Bahan organik total & 21,16 & $\mathrm{~S} 3$ & 1 & 33,3 \\
& & & & \\
\hline
\end{tabular}

Iklim:

50,0

\begin{tabular}{llllll}
\hline a. & Curah hujan (mm/tahun) & 2.251 & $\mathrm{S1}$ & 3 & 100,0 \\
b. & Lama bulan kering (bulan) & $<1$ & $\mathrm{~N}$ & 0 & 0
\end{tabular}

Daya Dukung Lingkungan: 67,36\% 
di Kecamatan Tabalar adalah kandungan fraksi liat dan $\mathrm{N}$ total tanah yang lebih baik dalam mendukung budi daya tambak.

Rata-rata kandungan $\mathrm{C}$ organik dan $\mathrm{PO}_{4}$ tanah tambak di Kecamatan Tabalar dan Biatan relatif sama dan tergolong rendah. Tanah tambak di Kecamatan Tabalar dan Biatan tergolong tanah sulfat masam, bukan tanah gambut sehingga kandungan $\mathrm{C}$ organiknya relatif rendah. Salah satu ciri tanah sulfat masam adalah $\mathrm{pH}$ tanah yang rendah sehingga kelarutan unsur Fe dan Al menjadi tinggi yang menyebabkan fosfor menjadi kurang atau tidak tersedia (Mustafa \& Sammut, 2007). Pada tanah yang pHnya rendah, $\mathrm{PO}_{4}$ diikat secara kuat oleh $\mathrm{Fe}$ dan $\mathrm{Al}$ dalam bentuk $\mathrm{FePO}_{4}$ atau $\mathrm{AIPO}_{4}$ yang tidak larut (Mustafa \& Sammut, 2007; Moriarty, 2010). Kandungan unsur hara lain dari tanah yang penting untuk budi daya tambak yaitu kandungan $\mathrm{N}$ total tanah menunjukkan konsentrasi yang lebih tinggi di Kecamatan Tabalar daripada Kecamatan Biatan.

Daya dukung lahan dari faktor kualitas air adalah sama di tambak Kecamatan Tabalar dan Biatan, yaitu $72,22 \%$. Akan tetapi tidak semua peubah kualitas air adalah sama di tambak di kedua kecamatan tersebut. Salinitas air yang lebih baik untuk mendukung budi daya tambak dijumpai di tambak Kecamatan Tabalar dan sebaliknya BOT yang lebih baik dalam mendukung budi daya tambak dijumpai di tambak Kecamatan Biatan. Udang windu, udang vaname (Litopenaeus vannamei), ikan bandeng, dan rumput laut (Gracilaria verrucosa) merupakan organisme eurihalin, namun karena dibudi dayakan untuk tujuan komersial, kisaran salinitas yang optimal perlu dipertahankan. Udang

Tabel 2. Daya dukung lingkungan di kawasan pertambakan Kecamatan Biatan, Kabupaten Berau, Provinsi Kalimantan Timur

\begin{tabular}{|c|c|c|c|c|c|c|}
\hline \multirow{2}{*}{\multicolumn{2}{|c|}{ Faktor/Peubah }} & \multirow[b]{2}{*}{$\begin{array}{l}\text { Nilai } \\
\text { Peubah }\end{array}$} & \multicolumn{3}{|c|}{ Penilaian Daya Dukung Lingkungan } & \multirow[b]{2}{*}{$\begin{array}{l}\text { Persentase } \\
\text { Kualitas Lahan }\end{array}$} \\
\hline & & & $\begin{array}{l}\text { Kelas } \\
\text { Kesesuaian }\end{array}$ & Skor & $\begin{array}{l}\text { Persentase } \\
\text { skor }\end{array}$ & \\
\hline \multicolumn{3}{|c|}{ Topografi dan Hidrologi: } & & & & 91,68 \\
\hline a. & Kemiringan (\%) & $<1,0$ & S1 & 3 & 100,0 & \\
\hline b. & Kestabilan pantai & Stabil & S1 & 3 & 100,0 & \\
\hline c. & Pasang surut (m) & 2,85 & $\mathrm{~S} 2$ & 2 & 66,7 & \\
\hline d. & Zona penyangga & $\begin{array}{l}>100 \mathrm{~m} \\
\text { dari area } \\
\text { proteksi }\end{array}$ & $\mathrm{S} 1$ & 3 & 100,0 & \\
\hline
\end{tabular}

\begin{tabular}{|c|c|c|c|c|c|c|c|}
\hline \multicolumn{7}{|c|}{ Kualitas Tanah: } & \multirow[t]{2}{*}{44,44} \\
\hline a. & $\begin{array}{l}\text { Kedalaman tanah } \\
\text { sampai mencapai } \\
\text { batuan }(\mathrm{m})\end{array}$ & $>2,0$ & S1 & & 3 & 100,0 & \\
\hline b. & Liat $(\%)$ & 23,2 & S2 & & 2 & 66,7 & \\
\hline c. & $\Delta \mathrm{pH}\left(\mathrm{pH}_{\mathrm{F}}-\mathrm{pH}_{\mathrm{FOX}}\right) 4,124$ & S3 & & 1 & 33,3 & & \\
\hline d. & C organik $(\%)$ & 4,238 & S3 & & 1 & 33,3 & \\
\hline e. & $\mathrm{N}$ total $(\%)$ & 0,340 & S3 & & 1 & 33,3 & \\
\hline f. & $\mathrm{PO}_{4}(\mathrm{ppm})$ & 23,505 & $\mathrm{~N}$ & & 0 & 0 & \\
\hline \multicolumn{7}{|c|}{ Kualitas Air: } & 72,22 \\
\hline a. & Suhu $\left({ }^{\circ} \mathrm{C}\right)$ & 29,56 & $\mathrm{~S} 1$ & & 3 & 100,0 & \\
\hline b. & Salinitas (ppt) & 11,08 & S2 & & 2 & 66,7 & \\
\hline c. & $\mathrm{pH}$ & 8,11 & S1 & & 3 & 100,0 & \\
\hline d. & Oksigen terlarut (mg/L) & 5,23 & S1 & & 3 & 100,0 & \\
\hline e. & $\mathrm{NH}_{3}(\mathrm{mg} / \mathrm{L})$ & 1,256 & $\mathrm{~N}$ & & 0 & 0 & \\
\hline f. & Bahan organik total $(\mathrm{mg} / \mathrm{L})$ & 18,46 & S2 & & 2 & 66,7 & \\
\hline \multicolumn{7}{|c|}{ Iklim: } & 50,0 \\
\hline a. & Curah hujan (mm/tahun) & 2.251 & $\mathrm{~S} 1$ & & 3 & 100,0 & \\
\hline b. & Lama bulan kering (bulan) & $<1$ & $\mathrm{~N}$ & & 0 & 0 & \\
\hline
\end{tabular}

Daya Dukung Lingkungan: $64,58 \%$ 
windu mampu menyesuaikan diri terhadap salinitas 3-45 ppt, namun untuk pertumbuhan optimal diperlukan salinitas 15-25 ppt (Poernomo, 1992). Udang vaname umumnya tumbuh optimal pada salinitas $15-20 \mathrm{ppt}$ (Bray et al., 1994). Ikan bandeng dan rumput laut tumbuh optimal pada salinitas 15 sampai 25 ppt. Dengan demikian, secara umum salinitas tambak di Kecamatan Tabalar lebih mendukung usaha budi daya tambak. Menurut Koesbiono (1981) kandungan BOT di air laut rata-rata rendah dan tidak melebihi $3 \mathrm{mg} / \mathrm{L}$. Kandungan BOT memengaruhi konsentrasi oksigen dalam air, karena peningkatan BOT akan mendorong aktivitas dekomposisi untuk menguraikan bahan organik menjadi anorganik dengan memanfaatkan oksigen. Kandungan BOT dalam budi daya udang sebaiknya tidak lebih dari $20 \mathrm{mg} / \mathrm{L}$ (TROBOS Aqua, 2016). Perairan dengan kandungan BOT di atas 26 $\mathrm{mg} / \mathrm{L}$ adalah tergolong subur (Reid, 1961).

Salah satu faktor yang sangat berpengaruh terhadap budi daya tambak termasuk daya dukung lingkungan tambak adalah iklim, terutama curah hujan dan jumlah bulan kering (curah hujan $<60 \mathrm{~mm} /$ bulan). Curah hujan bulanan di Kabupaten Berau dapat dilihat pada Gambar 2 dan menunjukkan bahwa setiap bulan terjadi hujan. Berdasarkan data curah hujan dari 2011 sampai dengan 2015, curah hujan di Kabupaten Berau rata-rata $2.251 \mathrm{~mm} /$ tahun dan bulan kering $<1$ bulan dalam setahun (4 bulan dalam 60 bulan). Curah hujan antara 2.000-3.000 mm/tahun dengan bulan kering 2-3 bulan dalam setahun merupakan kondisi iklim yang sangat mendukung budi daya tambak. Hasil penghitungan nilai $Q$ didapatkan sebesar 0,083 yang berarti Kabupaten Berau termasuk tipe Iklim A atau bersifat sangat basah. Hal ini terlihat juga pada Gambar 2, di mana ada rata-rata 19 hari hujan dalam sebulan di Kabupaten Berau yang menunjukkan bahwa hari hujan cukup tinggi. Kurangnya bulan kering dan tinggginya hari hujan menjadi faktor pembatas bagi budi daya tambak di Kabupaten Berau, sebab akan dijumpai masalah dalam pengeringan dasar tambak pada saat persiapan tambak. Oleh karena itu, daya dukung lahan dari faktor iklim di tambak Kecamatan Tabalar dan Biatan masing-masing sebesar $50,00 \%$. Analisis daya dukung dengan sistem pembobotan adalah salah satu metode yang digunakan dalam analisis daya dukung lingkungan tambak, selain metode analisis regresi polinomial dan metode yang mengacu pada kuantitas perairan. Hasil analisis daya dukung lingkungan menunjukkan bahwa daya dukung lingkungan tambak di Kecamatan Tabalar dan Biatan adalah dengan koefisien daya dukung lingkungan masing-masing 67,36 dan 64,58\% (Tabel 1,2 , dan 3). Dengan faktor dan peubah yang relatif sama, didapatkan koefisien daya dukung lingkungan tambak di Kabupaten Gresik, Provinsi Jawa Timur sebesar antara 78,7 dan 86,4\% (Prasita, 2007). Hal ini menunjukkan bahwa daya dukung lahan tambak di Kecamatan Tabalar dan Biatan, Kabupaten Berau relatif rendah dari tambak di Kabupaten Gresik.

Telah dilaporkan sebelumnya oleh Mustafa et al., (2011) bahwa berdasarkan hasil analisis kesesuaian lahan di Kabupaten Berau maka luas lahan tambak yang sesuai untuk budi daya tambak di Kecamatan Tabalar dan Biatan masing-masing 792,68 dan 59,62 ha (Tabel 3, Gambar 3 dan 4) yang semuanya tergolong kesesuaian lahan cukup sesuai. Oleh karena kedua

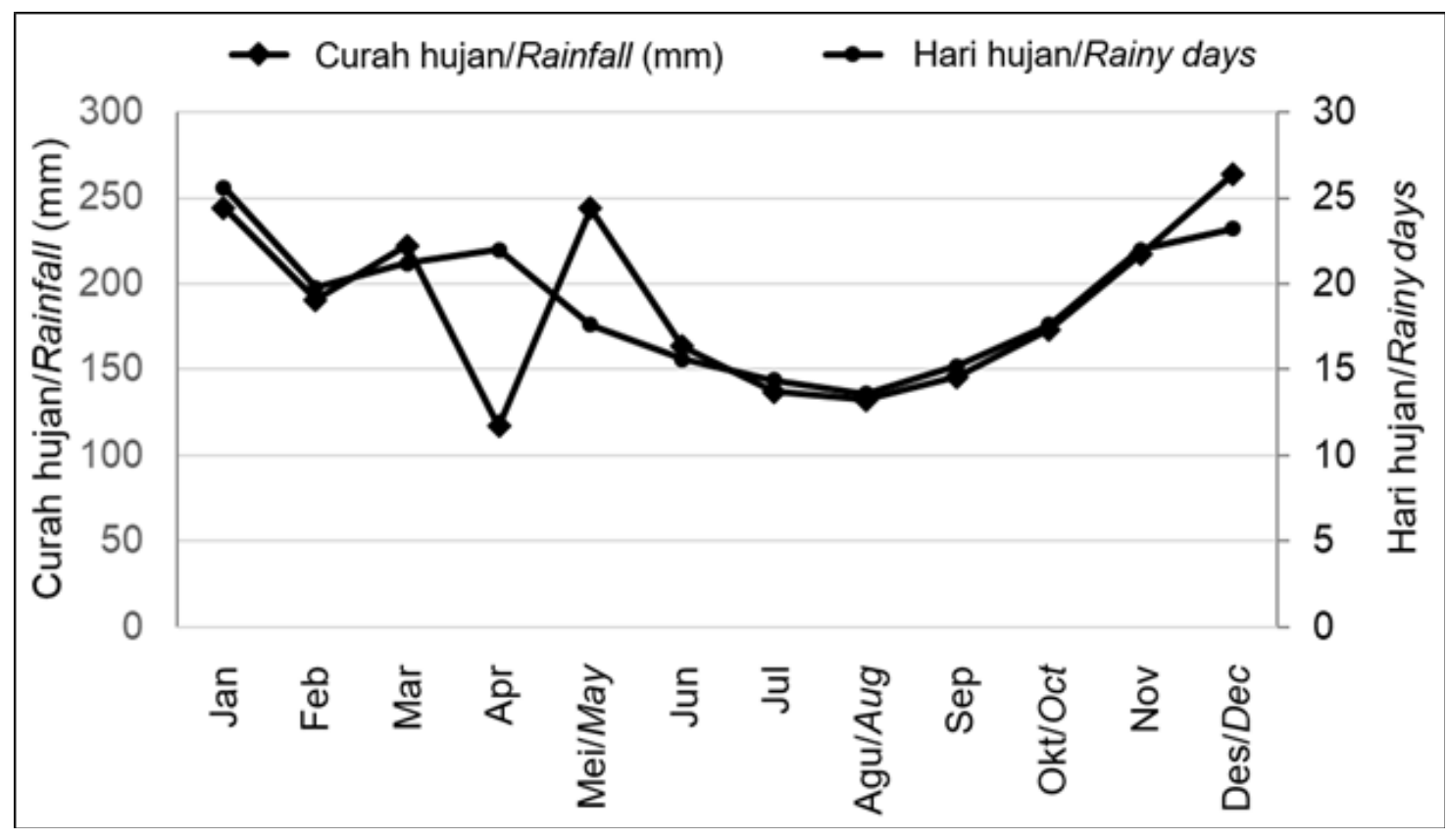

Gambar 2. Rata-rata curah hujan dan hari hujan bulanan dari 2011 sampai 2015 di Kabupaten Berau, Provinsi Kalimantan Timur. 
Tabel 3.

Luas lahan yang sesuai dan daya dukung lingkungan tambak di Kecamatan Tabalar dan Biatan, Kabupaten Berau, Provinsi Kalimantan Timur

\begin{tabular}{llll}
\hline Kecamatan & $\begin{array}{l}\text { Luas Lahan } \\
\text { yang Sesuai* } \\
\text { (ha) }\end{array}$ & $\begin{array}{l}\text { Koefisien } \\
\text { Daya Dukung } \\
\text { Lingkungan (\%) }\end{array}$ & $\begin{array}{l}\text { Luas Lahan } \\
\text { Berdasarkan } \\
\text { Daya Dukung (ha) }\end{array}$ \\
\hline $\begin{array}{l}\text { Tabalar } \\
\text { Biatan }\end{array}$ & $\begin{array}{l}792,68 \\
59,62\end{array}$ & 67,36 & $\begin{array}{l}533,95 \\
38,50\end{array}$ \\
\hline Total & & & 54,58
\end{tabular}

Sumber: *: Mustafa et al. (2011)

kecamatan tersebut masing-masing memiliki koefisien daya dukung lingkungan 67,36 dan 64,58\% (Tabel 1, 2 , dan 3 ), sehingga luas lahan yang dapat didukung yaitu 533,95 ha di Kecamatan Tabalar dan 38,50 ha di Kecamatan Biatan (Tabel 3). Daya dukung lingkungan dapat bervariasi pada spesies yang berbeda dan perubahan menurut waktu sebagai akibat berbagai faktor termasuk ketersediaan makanan, sumber air, kondisi lingkungan, dan ruang hidup (Ross et al., 2013). Dengan demikian, tambak yang tergolong kesesuaian lahan cukup sesuai, tetapi masih termasuk dalam jalur hijau atau sempadan sungai (lebarnya $100 \mathrm{~m}$ kiri kanan sungai sesuai Pasal 16 Keputusan Presiden Nomor 32 Tahun 1990 Tentang Pengelolaan Kawasan Lindung) agar dikonservasi melalui rehabilitasi atau reboisasi dengan menanam vegetasi mangrove (Sekneg RI, 1990). Kesesuaian dengan penggunaan lain, keberadaan daerah penyangga seperti kawasan lindung, mengatur suatu keseimbangan yang sesuai antara luas mangrove dan tambak, memperbaiki desain tambak, mengurangi pergantian air serta meningkatkan waktu tinggal dari air, ukuran dan kemampuan untuk mengasimilasi limbah dari badan air adalah contoh-contoh dari cara untuk mengurangi pengaruh-pengaruh yang merugikan (Páez-Osuna, 2001).

Hasil analisis penentuan faktor pembatas daya dukung lingkungan tambak di Kecamatan Tabalar menunjukkan bahwa peubah yang tergolong faktor pembatas sedang (S3) adalah $\Delta \mathrm{pH}$ tanah, $\mathrm{C}$ organik tanah, dan BOT air, sedangkan yang tergolong faktor pembatas berat $(\mathrm{N})$ adalah $\mathrm{PO}_{4}$ air, $\mathrm{NH}_{3}$ air, dan bulan kering. Dengan analisis yang sama didapatkan faktor pembatas daya dukung lingkungan tambak di Kecamatan Biatan yang tergolong faktor pembatas sedang (S3) adalah $\Delta \mathrm{pH}$ tanah, C organik tanah, dan $\mathrm{N}$ total tanah, sedangkan yang tergolong faktor pembatas berat (N) sama dengan di Kecamatan Tabalar yaitu $\mathrm{PO}_{4}$ tanah, $\mathrm{NH}_{3}$ air, dan bulan kering. Dari faktor

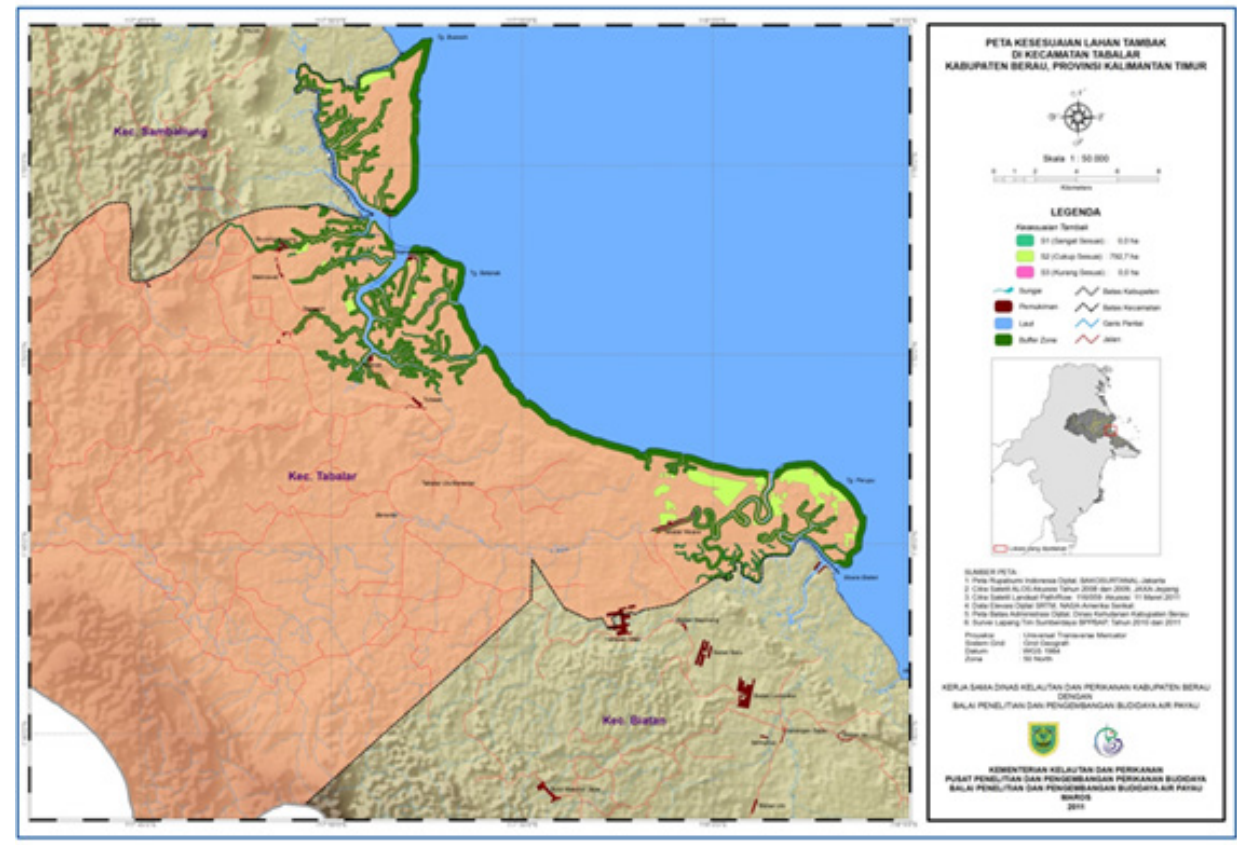

Gambar 3. Peta kesesuaian lahan aktual untuk budidaya tambak di Kecamatan Tabalar, Kabupaten Berau, Provinsi Kalimantan Timur (Mustafa et al., 2011). 
pembatas daya dukung lingkungan yang tergolong faktor pembatas sedang dan berat ini ada yang dapat bersifat permanen dan nonpermanen. Faktor pembatas yang bersifat permanen seperti bulan kering merupakan faktor pembatas yang sulit diperbaiki, sedangkan faktor pembatas nonpermanen merupakan faktor pembatas yang masih dapat diperbaiki seperti: $\Delta$ $\mathrm{pH}$ tanah, $\mathrm{C}$ organik tanah, $\mathrm{N}$ total tanah, $\mathrm{PO}_{4}$ tanah, dan BOT air, $\mathrm{PO}_{4}$ air, dan $\mathrm{NH}_{3}$ air.

Berdasarkan berbagai faktor pembatas yang tergolong sedang dan berat itu maka ditentukan pengelolaan lahan yang dapat dilakukan untuk meningkatkan kualitas lahan tambak di Kecamatan Tabalar dan Biatan. Dengan potensi keasaman tanah yang tinggi yang dicirikan dengan $\Delta \mathrm{pH}$ tanah yang tinggi dan $\mathrm{pH}$ tanah yang rendah menyebabkan kelarutan berbagai senyawa toksin seperti $\mathrm{Fe}$ dan Al tanah menjadi lebih tinggi yang berdampak pula pada rendahnya ketersediaan unsur tertentu seperti fosfor. Untuk mengurangi $\Delta \mathrm{pH}$ tanah dan meningkatkan $\mathrm{pH}$ tanah dapat dilakukan dengan remediasi yaitu remediasi dalam bentuk pengeringan, perendaman, dan pembilasan. Prinsip remediasi melalui pengeringan, perendaman dan pembilasan tanah: pengeringan tanah untuk mengoksidasi pirit, perendaman untuk melarutkan dan menetralisir keasaman atau menurunkan produksi keasaman lanjut, dan pembilasan untuk membuang hasil oksidasi dan meminimalkan cadangan unsur-unsur beracun dalam tanah. Agar proses remediasi ini lebih efektif, maka sebaiknya dilakukan pada musim kemarau agar proses pengeringan tanah dapat lebih baik dan air yang digunakan untuk perendaman bersalinitas lebih tinggi.
Air bersalinitas lebih tinggi lebih efektif digunakan dalam proses remediasi tanah sulfat masam (Mustafa \& Sammut, 2007). Bentuk lain dari remediasi yang dapat menurunkan $\Delta \mathrm{pH}$ tanah dan meningkatkan $\mathrm{pH}$ tanah adalah pengapuran.

Kandungan $\mathrm{N}$ total dan $\mathrm{PO}_{4}$ tanah yang tergolong rendah dapat ditingkatkan melalui pemupukan. Dengan mempertimbangkan kandungan $\mathrm{N}$ total dan $\mathrm{PO}_{4}$ tanah (Tabel 1 dan 2) dan petunjuk Mustafa et al. (2015), maka dosis pupuk yang disarankan untuk tambak di Kecamatan Tabalar dan Biatan sebesar 150 Urea/ ha/siklus dan $125 \mathrm{~kg} \mathrm{SP}-36 /$ ha/siklus. Kandungan C organik tanah yang rendah dapat ditingkatkan melalui pemberian pupuk organik. Secara umum terlihat bahwa faktor pembatas tanah dapat diminimalkan dengan upaya berupa peningkatan kesuburan tanah.

Peubah kualitas air yang menjadi faktor pembatas daya dukung lingkungan tambak di Kecamatan Tabalar dan Biatan adalah BOT dan $\mathrm{NH}_{3}$ air. Panjaitan (1991) menyatakan, bahwa peningkatan kandungan BOT air merupakan pemicu kematian larva udang windu di panti benih. Boyd (1990) melaporkan, bahwa daya racun $\mathrm{NO}_{2}$ yang ada dalam perairan sangat dipengaruhi oleh kandungan $\mathrm{NH}_{3}$-nya, di mana jika kandungan kedua peubah tersebut tinggi, maka secara bersama-sama keduanya merupakan pemicu stres pada udang dan ikan yang dibudidayakan, sehingga udang dan ikan lebih rentan terserang penyakit. Untuk menurunkan kandungan BOT air dapat dilakukan dengan mengaplikasikan probiotik terutama probiotik mengandung jenis bakteri, seperti Bacillus firmus, Brevibacillus laterosporus, Vibrio

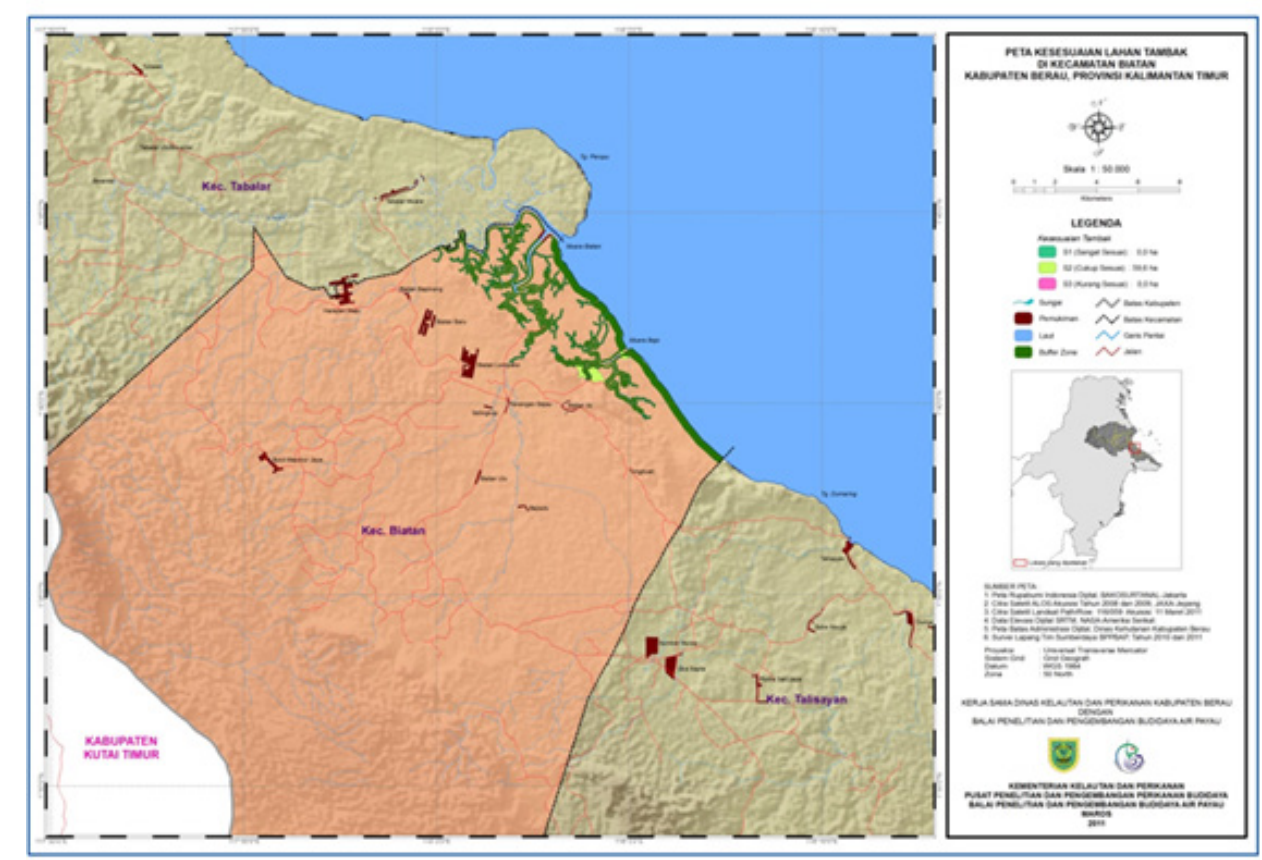

Gambar 3. Peta kesesuaian lahan aktual untuk budi daya tambak di Kecamatan Tabalar, Kabupaten Berau, Provinsi Kalimantan Timur (Mustafa et al., 2011). 
vulnificus, Serratia marcescens, dan Psychrobacter $s p$. yang memang memiliki kemampuan mengurai bahan organik (Atmomarsono et al., 2009). $\mathrm{NH}_{3}$ dapat dikurangi secara langsung melalui asimilasi bakteri heterotropik, alga, dan tanaman air lainnya (Kuhn et al., 2011). Probiotik adalah bakteri heterotropik yang biasa diberikan pada budi daya tambak, karena memiliki kemampuan memperbaiki kualitas air tambak seperti menurunkan $\mathrm{BOT}, \mathrm{NH}_{3}$, dan $\mathrm{NO}_{2}$ air (Mustafa et al., 2015) atau secara umum diperlukan upaya pengelolaan air yang tepat. Melalui pengelolaan lahan yang tepat pada faktor pembatas nonpermanen, maka faktor pembatas berat $(\mathrm{N})$ dapat dikurangi dan menjadi faktor pembatas sedang (S3), atau faktor pembatas ringan (S2), atau tanpa faktor pembatas (S1) dan demikian juga halnya faktor pembatas sedang (S3) dapat dikurangi dan menjadi faktor pembatas ringan (S2), atau tanpa faktor pembatas (S1). Dengan demikian, daya dukung lahan tambak di Kecamatan Tabalar dan Biatan dapat ditingkatkan.

Tidak adanya bulan kering menyebabkan persiapan tambak sangat sulit dilakukan. Persiapan tambak adalah salah satu kegiatan yang harus dilakukan sebelum dilakukan penebaran. Pada saat persiapan tambak dilakukan pengeringan tambak dengan tujuan untuk memperbaiki sifat fisik tanah, meningkatkan mineralisasi bahan organik dan menghilangkan bahanbahan beracun berupa hidrogen sulfida, amonia, dan metan. Pengeringan tanah tambak sebagai salah satu bagian dari remediasi juga akan mengalami kendala dengan tidak adanya bulan kering. Iklim termasuk lama bulan kering sering menjadi faktor pembatas berat untuk kegiatan pertanian, kehutanan, dan perikanan (Holland, 1972).

\section{KESIMPULAN}

Berdasarkan analisis menunjukkan bahwa daya dukung lingkungan di kawasan tambak di Kecamatan Tabalar dan Biatan, Kabupaten Berau, Provinsi Kalimantan Timur masing-masing 67,36 dan 64,58\%, sehingga luas tambak yang dapat didukung berturutturut 533,95 dan 38,50 ha. Di tambak Kecamatan Tabalar dan Biatan didapatkan faktor pembatas sedang dari daya dukung lingkungan berupa $\Delta \mathrm{pH}$ $\left(\mathrm{pH}_{\mathrm{F}}-\mathrm{pH}_{\mathrm{FOX}}\right)$ tanah, $\mathrm{C}$ organik tanah, $\mathrm{N}$ total tanah, dan bahan organik total air, sedangkan faktor pembatas berat berupa $\mathrm{PO}_{4}$ air, $\mathrm{NH}_{3}$ air, dan bulan kering. Untuk mengurangi faktor pembatas sehingga meningkatkan daya dukung lingkungan tambak disarankan untuk menerapkan konservasi lahan, meningkatkan kesuburan tanah, dan mengelola air secara tepat.

\section{PERSANTUNAN}

Penelitian ini dilaksanakan atas kerja sama Dinas Kelautan dan Perikanan Kabupaten Berau dengan Balai Penelitian dan Pengembangan Budidaya Air Payau, Maros. Untuk itu, diucapkan terima kasih kepada Dinas Kelautan dan Perikanan Kabupaten Berau atas pendanaanya dan bantuannya selama pelaksanaan penelitian ini. Akhmad Mustafa berperan sebagai kontributor utama dalam karya tulis ilmiah ini,

\section{DAFTAR PUSTAKA}

Agus, F., Yusrial, \& Sutono. (2006). Penetapan tekstur tanah. Dalam: Kurnia, U., Agus, F., Adimihardja, A., \& Dariah, D. (eds.), Sifat Fisik Tanah dan Metode Analisisnya. Bogor: Balai Besar Penelitian dan Pengembangan Sumberdaya Lahan Pertanian. hlm. 43-62.

Ahern, C.R., Blunden, B., Sullivan, L.A., \& McElnea, A.E. (2004). Soil sampling, handling, preparation and storage for analisys of dried samples. In: Acid Sulfate Soils Laboratory Methods Guidelines. Indooroopilly, Queensland: Queensland Department of Natural Resources, Mines and Energy. pp. B1-1-B1-5.

Alifatri, L.O., Hariyadi, S. \& Susanto, H.A. (2017). Analisis daya dukung lahan untuk pengembangan budi daya kerapu di perairan tambak Kecamatan Cilebar, Kabupaten Karawang. Jurnal IImu Pertanian Indonesia, 22(1), 52-66.

American Public Health Association [APHA]American Water Works Association [AWWA]Water Environment Federation [WEF]. (2012). Standard Methods for the Examination of Water and Wastewater. $22^{\text {nd }}$ Edition. Washington, D.C.: American Public Health Association - American Water Works Association - Water Environment Federation. $1360 \mathrm{pp}$.

Atmomarsono, M., Muliani., \& Nurbaya. (2009). Penggunaan bakteri probiotik dengan komposisi berbeda untuk perbaikan kualitas air dan sintasan pascalarva udang windu. Jurnal Riset Akuakultur, 4(1), 73-83.

Bengtson, D.A. (2014). Aquaculture carrying capacity and water quality in Indonesian lakes and reservoirs - A new project. Aquacultura Indonesiana,15(2), 46-50.

Boyd, C.E. (1990). Water Quality in Ponds for Aquaculture. Birmingham, Alabama, USA: Birmingham Publishing Co. 482 pp.

Boyd, C.E. (1995). Bottom Soils, Sediment, and Pond Aquaculture. New York: Chapman and Hall. 348 $\mathrm{pp}$. 
Boyd, C.E., Wood, C.W., \& Thunjai, T. (2002). Aquaculture Pond Bottom Soil Quality Management. Corvallis, Oregon: Pond Dynamics/ Aquaculture Collaborative Research Support Program Oregon State University. 41 pp.

Bray, W.A., Lawrence, A.L., \& Leung-Trujillo, J.R. (1994). The effect of salinity on growth and survival of Penaeus vannamei, with observations on the interaction of $\mathrm{IHHN}$ virus and salinity. Aquaculture, 122, 133-146.

Dinas Kelautan dan Perikanan [DKP] Kabupaten Berau. (2010). Laporan Statistik Perikanan 2009. Tanjung Redeb: Pemerintah Kabupaten Berau, Dinas Kelautan dan Perikanan. $87 \mathrm{hlm}$.

Eviati \& Sulaeman. (2009). Analisis Kimia Tanah, Tanaman, Air, dan Pupuk. Bogor: Balai Penelitian Tanah. $234 \mathrm{hlm}$.

Holland, W.D. (1972). Limiting Factors in Land and Soil Capability Assessment. Edmonton, Alberta: Northern Forest Research Centre, Environment Canada. 30 pp.

KKPNews. (2018). Berau tingkatkan potensi budi daya perikanan tambak. KKPNews, 23 Juni 2018. https://news.kkp.go.id/index.php/berautingkatkan-potensi-budi daya-perikanan-tambak/. [Diakses 26 Desember 2018].

Koesbiono. (1981). Biologi Laut. Bogor: Fakultas Perikanan, Institut Pertanian Bogor. 150 hlm.

Kuhn, D.D., Smith, S.A., \& Flick, G.J. (2011). High nitrate levels toxic to shrimp. The Global Aquaculture Advocate, November/December, 3637.

McCarty, D.F. (1998). Essentials of Soil Mechanics and Foundations. New Jersey: Prentice Hall, Upper Saddle River. 730 pp.

McKindsey, C.W., Thetmeyer, H., Landry, T., \& Silvert, W. (2006). Review of recent carrying capacity models for bivalve culture and recommendations for research and management. Aquaculture, 261(2), 451-462.

Moretto, L. \& Francis, C.M. (2017). What factors limit bat abundance and diversity in temperate, North American urban environments. Journal of Urban Ecology, 3(1), 1-9. https://doi.org/10.1093/jue/ jux016

Moriarty, D.J.W. (2010). Sulphide and phosphate problems in shrimp ponds. AQUA Culture Asia
Pacific, 6(5), 42-45.

Mustafa, A. (2012). Kriteria kesesuaian lahan untuk berbagai komoditas di tambak. Media Akuakultur, 7(2), 108-118.

Mustafa, A., Mangampa, M., \& Ratnawati, E. (2015). Panen Untung dari Produksi Tokolan Udang dalam Waktu Singkat. Yogyakarta: Andi Offset. $178 \mathrm{hlm}$.

Mustafa, A., Rachmansyah, Ratnawati, E., Hasnawi, Asaad, A.I.J., Paena, M., \& Makmur. (2011). Kajian Daya Dukung Lahan Budi daya Tambak di Kabupaten Berau, Provinsi Kalimantan Timur. Laporan Akhir. Kerja Sama Dinas Kelautan dan Perikanan Kabupaten Berau dengan Balai Penelitian dan Pengembangan Budidaya Air Payau. Maros: Balai Penelitian dan Pengembangan Budi daya Air Payau. 120 hlm.

Mustafa, A. \& Sammut, J. (2007). Effect of different remediation techniques and dosages of phosphorus fertilizer on soil quality and klekap production in acid sulfate soil-affected aquaculture ponds. Indonesian Aquaculture Journal, 2(2), 141-157.

Neto, R.M., Nocko, H.R., \& Ostrensky, A. (2016). Carrying capacity and potential environmental impact of fish farming in the cascade reservoirs of the Paranapanema River, Brazil. Aquaculture Research, 2016, 1-17. DOI:10.1111/are.13169

Páez-Osuna, F. (2001). The environmental impact of shrimp aquaculture: causes, effects, and mitigating alternatives. Environmental Management, 28(1), 131-140.

Panjaitan, P.J. (1991). Serangan Penyakit Kunangkunang pada Larva Udang Windu (Penaeus monodon Fabricus) di Panti Benih Daerah Situbondo, Jawa Timur. Tesis. Bogor: Program Studi IImu Perairan, Fakultas Pascasarjana, Institut Pertanian Bogor. 99 hlm.

Poernomo, A. (1992). Pemilihan Lokasi Tambak Udang Berwawasan Lingkungan. Seri Pengembangan Hasil Penelitian No. PHP/KAN/PATEK/004/1992. Jakarta: Badan Penelitian dan Pengembangan Pertanian. $40 \mathrm{hlm}$.

Prasita, V.D. (2007). Analisis Daya Dukung Lingkungan dan Optimalisasi Pemanfaatan Wilayah Pesisir untuk Pertambakan di Kabupaten Gresik. Disertasi. Bogor: Sekolah Pascasarjana, Institut Pertanian Bogor. $147 \mathrm{hlm}$. 
Rahayu, A.P. (2017). Daya dukung lahan tambak budi daya ikan kerapu (Ephinepelus spp) di Kecamatan Brondong, Kabupaten Lamongan. Jurnal Grouper, 18(1), 13-19.

Reid, G.K. (1961). Ecology of Inland Water Estuaries. New York: Rein Hald Published Co. 37 pp.

Ross, L.G., Telfer, T.C., Falconer, L., Soto, D., AguilarManjarrez, J., Asmah, R., Bermúdez, J., Beveridge, M.C.M., Byron, C.J., Clément, A., Corner, R., Costa-Pierce, B.A., Cross, S., De Wit, M., Dong, S., Ferreira, J.G., Kapetsky, J.M., Karakassis, I., Leschen, W., Little, D., Lundebye, A.-K., Murray, F.J., Phillips, M., Ramos, L., Sadek, S., Scott, P.C., Valle-levinson, A., Waley, D., White, P.G. \& Zhu, C. (2013). Carrying capacities and site selection within the ecosystem approach to aquaculture. In: Ross, L.G., Telfer, T.C., Falconer, L., Soto, D., \& Aguilar-Manjarrez, J. (eds.), Site Selection and Carrying Capacities for Inland and Coastal Aquaculture. FAO/Institute of Aquaculture, University of Stirling, Expert Workshop, 6-8 December 2010. Stirling, the United Kingdom of Great Britain and Northern Ireland. FAO Fisheries and Aquaculture Proceedings No. 21. Rome: FAO. pp. 19-46.

Sekretariat Negara Republik Indonesia [Sekneg RI]. (1990). Keputusan Presiden Republik Indonesia Nomor 32 Tahun 1990 Tentang Pengelolaan Kawasan Lindung. Jakarta: Sekretariat Negara Republik Indonesia. $14 \mathrm{hlm}$.

Sekretariat Negara Republik Indonesia [Sekneg RI]. (2008). Peraturan Pemerintah Republik Indonesia Nomor 26 Tahun 2008 Tentang Rencana Tata Ruang Wilayah Nasional. Jakarta: Sekretariat Negara Republik Indonesia. 70 hlm.

Schmidt, F.H. \& Ferguson, J.H.A. (1951). Rainfall type based on wet and dry period ratios for Indonesia with Western New Gurinea. Verhandelingen, 42: 77 pp. plus figures.

Smaal, A.C. \& van Duren, L.A. (2018). Bivalve aquaculture carrying capacity: concepts and assessment tools. In: Smaal, A.C., Ferreira, J.G., Grant, J., Petersen, J.K., \& Strand, Ø. (eds.), Goods and Services of Marine Bivalves. Cham: Springer. pp. 451-483.

Stigebrandt, A. (2011). Carrying capacity: general principles of model construction. Aquaculture Research, 42, 41-50. DOI:10.1111/j.13652109.2010.02674.x

Susetyo, A.D. \& Santoso, E.B. (2016). Kesesuaian lahan perikanan tambak berdasarkan faktor- faktor daya dukung fisik di Kabupaten Sidoarjo. Jurnal Teknik ITS, 5(1), C18-C22.

Sutrisyani \& Rohani, S. (2009). Panduan Praktis Analisis Kualitas Air Payau. Cetakan kedua. Diedit: Rachmansyah, Atmomarsono, M., \& Mustafa, A. Jakarta: Pusat Riset Perikanan Budidaya. $55 \mathrm{hlm}$.

Sys, C., van Ranst, E., Debaveye, J., \& Beernaert, F. (1993). Land Evaluation Part III: Crop Requirements. Agricultural Publication No. 7. Brussels-Belgium: General Administration for Development Cooperation. 201 pp.

Triyatmo, B., Rustadi, \& Priyono, S.B. (2018). Characteristics and environmental carrying capacities of coastal area in Yogyakarta Special Region for aquaculture. IOP Conference Series: Earth and Environmental Science, 139, 1-10.

TROBOS Aqua (2016). Siasati kandungan bahan organik tambak. TROBOS Aqua Edisi-52/15 September-14 Oktober 2016, Kamis, 15 September 2016. $1 \mathrm{hlm}$.

Yulianda, F. (2008). Kajian kesesuaian dan daya dukung lingkungan tambak berbasis spasial di wilayah pesisir Kabupaten Aceh Utara, pantai timur Provinsi Nanggroe Aceh Darussalam. Jurnal Ilmu-ilmu Perairan dan Perikanan Indonesia, 15(2), 157-163. 